\title{
Os objetivos constitucionais de preparo para o exercício da cidadania ativa em contexto de declínio do cidadão participativo no Estado Democrático de Direito
}

\author{
Regina Celli Marchesini Berardi ${ }^{1}$
}

Resumo: O presente artigo trata da importância da participação política (como expressão da cidadania) para a democracia e da educação como um dos instrumentos para promover a participação política. Este estudo surge face à preocupação com a apatia e o desinteresse pela participação e pelas coisas públicas, com o escopo de contribuir para a reflexão sobre o papel da educação, sobretudo por meio da educação cívica escolar, na formação do cidadão participativo, condição imprescindível para a sedimentação do regime democrático. A proposta fundamenta-se nas exigências constitucionais de preparo para a cidadania e a participação, as quais tem a cidadania como um dos fundamentos do Estado Democrático de Direito. Abordar-se-ão os temas de "cidadania", "participação política", "democracia" e "educação formal básica", para discutir se o direito à educação, conforme está garantido nas Constituições Brasileira é suficiente e adequado para atingir o objetivo da participação política ou, se é necessária uma educação política específica, que vá além da mera instrução fornecida pelos Estados para a efetiva promoção da cidadania ativa.

Palavras-chave: cidadania, participação política, democracia, educação.

\section{Constitutional objectives for preparation to exercise an active citizenship in a context of declining participative citizens in Democratic State of Law}

\begin{abstract}
This dissertation addresses the importance of political participation (as an expression of citizenship) to democracy and education as an instrument for promoting political participation. This study compared the concern arises with the apathy and disinterest in participation and public things, with the aim of contributing to the debate on the role of education, particularly through the school civic education, training, participatory citizen, essential condition for sedimentation of the democratic regime. The proposal is based
\end{abstract}

\footnotetext{
${ }^{1}$ Graduada em Direito pela Faculdade de Direito de Franca (2010), Mestre em Direito Constitucional pela Universidade de Coimbra-Portugal (2014), Especialista em Psicologia Multifocal no Centro de Gestão Empreendedora - FEAD (2015), Doutoranda em Direito Penal pela USAL - Universidade de Salamanca- Espanha, Advogada e Professora. E-mail: recmberardi@hotmail.com
} 
on the Constitutional requirements of preparation for citizenship and participation, which has citizenship as a cornerstone of a democratic state. Will address up-themes of "citizenship", "political participation", "democracy" and "formal basic education", in order to discuss the right to education, as it is guaranteed in the Brazilian's Constitution, is sufficient and appropriate to achieve the goal of political participation or if a specific political education that goes beyond the mere statement provided by the States for the effective promotion of active citizenship is required.

Keyword: citizenship, political participation, democracy, education.

\section{INTRODUÇ̃̃̃O}

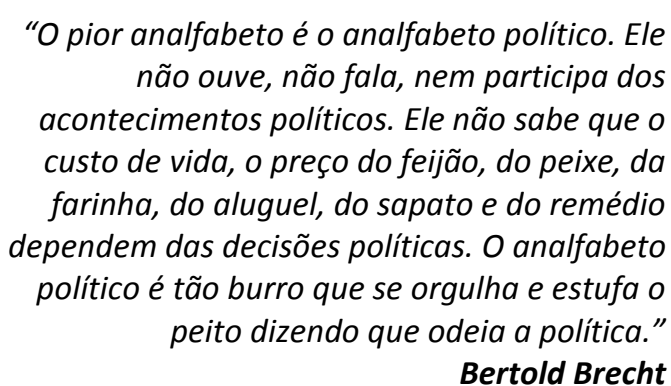

A prossecução da equidade, da coesão social e dos valores democráticos constitui uma prioridade política que, nos últimos anos, tem vindo a adquirir crescente importância em nível internacional $^{2}$. Uma das suas principais exigências é a de que os cidadãos, principalmente os jovens, sejam incentivados a participar ativamente na vida política. É neste cenário que vários documentos políticos relevantes reconheceram a importância de promover a cidadania ativa, a qual passou a ser, por isso, um dos principais objetivos dos sistemas educativos do mundo.

De fato, a educação voltada para a cidadania é eficaz instrumento de consciência política e emancipação social, necessária à efetivação da democracia. Consubstanciado nisso, vários dispositivos presentes nas Constituições Brasileiras, bem como garantidos em

\footnotetext{
${ }^{2}$ A importância do tema e o apelo internacional para a prossecução desses objetivos é tão significativo que a Assembleia Geral da Organização das Nações Unidas (ONU) proclamou que o dia 15 de setembro seria o Dia Internacional da Democracia, comemorado desde 2008, com a intenção de impulsionar o reconhecimento universal e a necessidade da livre expressão da vontade dos povos, expressados pela liberdade política, econômica, social e cultural plena, bem como pela igualdade de participação de todos os cidadãos em todos os âmbitos da vida em sociedade. Interessante dizer que a ONU concebe a democracia como um de seus valores fundamentais e, procurando dar a ela a devida relevância, incorporou seus princípios em vários de seus documentos, como por exemplo, verifica-se na Declaração Universal dos Direitos Humanos, no Pacto Internacional dos Direitos Civis e Políticos, no Estatuto do Tribunal Penal Internacional, consagrando diversos direitos políticos e beneficiando as liberdades civis, como pilar de sustentação da democracia.
}

Saber Humano - Revista Científica da Faculdade Antonio Meneghetti. 
documentos internacionais, enunciam e fundamentam a difusão e a promoção do princípio democrático como fundamento do Estado, tornando-se o conteúdo nuclear do direito à educação.

A educação corresponde antes de tudo a uma necessidade social, seja ela individual ou coletiva e, seu conceito, no Estado Democrático de Direito, não pode ser desvinculado dos objetivos e fundamentos da República. Assim, a educação tem entre suas missões a de desenvolver o ser humano na sua dimensão social, sendo considerada por alguns o "maior poder e a maior responsabilidade mundial"3.

Todavia, há ausência de uma "ética grupal" em nossas sociedades e uma das formas de buscar corrigir essa carência de adesão dos membros de uma comunidade é incutir-lhes o sentimento de pertença, como sujeitos de uma sociedade justa. Isso porque, segundo Adela Cortina, todos são vítimas de uma mesma crise, corresponsáveis pelo enfraquecimento do tecido social ${ }^{4}$.

Com efeito, o presente estudo propõe uma análise constitucional dos objetivos educacionais de participação política. A relevância social desta pesquisa está na necessidade de alcançar uma sociedade mais comprometida com as questões públicas que atualmente é composta por uma parcela de cidadãos apáticos, inativos que aceitam passivamente as injustiças, a corrupção e a miserabilidade.

Dessa forma, acredita-se que quando se busca uma maior participação na vida coletiva e não apenas na esfera política, o que se quer assegurar é a própria sobrevivência da democracia e da concretização da cidadania plena em seu sentido amplo, qual seja, aquele que entende a cidadania como direito habilitante de outros direitos.

\section{NOVA CIDADANIA: conceito de cidadania ativa e sua ideia de participação}

A ideia de cidadania ativa afirmou-se historicamente com o desenvolvimento dos movimentos sociais, com a expansão dos movimentos de massas e com a luta pela conquista dos direitos universais.

Em relação às concepções modernas de cidadania, pode-se dizer que elas se concentram ora na participação política, ora na garantia de direitos. Segundo Comparato: " $a$

\footnotetext{
${ }^{3}$ Esse é o entendimento de Agostinho Reis Monteiro que diz que "O direito à educação é o maior poder e a maior responsabilidade do mundo, porque o mundo é feito pelos seres humanos e um ser humano é o seu nome, o seu rosto, o seu corpo e tudo o que a sua educação gerar dentro de si". (Disponível em: http://reismonteiro.net/site/. Acesso em 18/06/2013). Nesse sentido também Nelson Mandela, acreditando no poder e na responsabilidade da educação disse uma vez que "a educação é a arma mais poderosa que você pode usar para mudar o mundo".

${ }^{4}$ CORTINA, 1997.
}

Saber Humano - Revista Científica da Faculdade Antonio Meneghetti. 
ideia-mestra da nova cidadania consiste em fazer com que o povo se torne parte principal do processo de seu desenvolvimento e promoção social: é a ideia de participação ${ }^{5}$ ".

Consubstanciado nessa visão esse conceito prioriza a cidadania ativa, qual seja, aqueles que requerem a "participação popular como possibilidade de criação, transformação e controle sobre o poder ou os poderes" e ela depende do direito à educação ${ }^{6}$. Assim, o direito à cidadania corresponde, entre outros, ao direito de votar e ser votado, de participar de processos eleitorais, mas diz respeito também ao pleno exercício da liberdade e, ainda, a "possibilidade concreta e não apenas teórica ou legal de participação na vida social com poder de influência e de decisão ${ }^{7, "}$.

Essa nova concepção de cidadania é meio eficaz e imprescindível para o exercício da democracia, pois permite que o cidadão saia da posição de passividade e espectador das ações do Estado e se torne sujeito ativo de suas decisões, fiscalize a atuação dos servidores públicos e agentes políticos, participe de audiências públicas e elabore juízos de valor, assumindo a posição de coautor e participante ativo em sociedade ${ }^{8}$.

Na cidadania ativa, o cidadão tem "direito a ter direito" $9 "$ e nos dizeres de Dallari, ela expressa um conjunto de direitos que dá à pessoa a possibilidade de participar ativamente da vida e do governo de seu povo ${ }^{10}$, sendo esses atributos essenciais para o fortalecimento da democracia.

\section{A PARTICIPAÇÃO POLÍTICA PARA O FORTALECIMENTO DA DEMOCRACIA PARTICIPATIVA}

De forma geral, a participação política define-se como toda atividade dos cidadãos dirigida a intervir na designação de seus governantes ou a influir na formação da política estatal. Correspondem às ações coletivas ou individuais, legais ou ilegais, de apoio ou de pressão, por meio das quais uma ou muitas pessoas pretendem influir nas decisões a respeito do tipo de governo que deve reger uma sociedade, no modo como se dirige ao Estado em cada país, ou em decisões específicas do governo que afetam uma comunidade ou seus membros individuais.

\footnotetext{
${ }^{5}$ COMPARATO, 1993, p. 85-106.

${ }^{6}$ BENEVIDES, 1991, p.20.

${ }^{7}$ DALLARI, 2009, p. 345.

${ }^{8}$ COSTA, 2011.

9 O conceito de Hanna Arendt de cidadania como "direito a ter direitos" é entendido tanto no sentido de ter direitos e ter como usufruí-los, bem como gozá-los e fazer com que eles sejam causa de novos direitos permanentemente (ARENDT, 1989, p.330).

10 DALLARI, Dalmo de Abreu. Direitos e Deveres de Cidadania. Disponível em $<$ http://www.dhnet.org.br/direitos/sos/textos/deveres.htm> Acesso em 29/04/2014
}

Saber Humano - Revista Científica da Faculdade Antonio Meneghetti. 
Diante da multiplicidade de sentidos existentes para o termo, para a presente abordagem cumpre tratar o seu significado de maneira vulgar, correspondendo a uma tendência para os indivíduos se desinteressarem por matérias políticas, que por sua vez, pode ser explicada por causas muito diversas. Em síntese corresponde ao conjunto de ações cívicas que incluem o exercício do direito de voto e demais direitos políticos, a manifestação pública e a intervenção nas mais diversas organizações e associações de interesses da sociedade civil.

Sem se esquecer das particularidades de cada uma das formas de participação política, todas assumem a mesma importância, haja vista que "todas contribuem, cada uma à sua maneira, para a realização dos ideais da democracia participativa. ${ }^{11}$ ",

Ressalta-se que a atual Constituição Brasileira consagra o regime da democracia semidireta $^{12}$ ou participativa, haja vista que os cidadãos elegem seus representantes através do voto, bem como possuem garantidos mecanismos de participação popular direta. Neste trabalho, parte-se do entendimento de que a Democracia Participativa ${ }^{13}$ é aquela que se apresenta tanto pelo exercício do poder mediante a representação quanto diretamente. Adotase o conceito de democracia participativa como sinônimo de democracia semidireta.

A participação é a base da democracia que cria hábitos interativos e esferas de deliberação pública as quais permitem a consecução de indivíduos autônomos e que exercem o controle. Sobre a importância do exercício do controle, Adalberto Alves ao tratar da democracia e da participação popular, citando Karl Popper, enuncia que "a coisa mais importante acerca da democracia não é a participação de todos no poder, mas a possibilidade de substituir pacificamente os maus governos".

Acredita-se que quanto mais pessoas participem desse processo, maior será a fortaleza $^{14}$ da democracia, melhorando o funcionamento do sistema. A participação política, embora garantida constitucionalmente e apesar dos avanços importantes para promovê-la,

\footnotetext{
${ }^{11}$ MARTINS, 2010, p. 243.

${ }^{12}$ No tocante à democracia semidireta ou participativa, Pedro Lenza a define como sendo "um sistema híbrido, uma democracia representativa, com peculiaridades e atributos da democracia direta (LENZA, 2010, p.869), a qual constitui conforme Mônica de Melo um mecanismo capaz de propiciar além da participação direta, concreta do cidadão na democracia representativa, controle popular sobre os atos estatais (Revista da PGE/SP, 336, dez 1993)".

${ }^{13}$ Sobre esse assunto Gomes Canotilho e Vital Moreira entendem que a democracia participativa corresponde à intervenção dos cidadãos, individualmente ou, sobretudo, por meio de organizações sociais ou profissionais nas tomadas de decisões das instâncias do poder, ou nos próprios órgãos de poder. (CANOTILHO \& MOREIRA, 1993).

14 Segundo Boaventura, para o fortalecimento da democracia deve existir: a) o fortalecimento da demodiversidade, devendo o sistema político abrir mão de prerrogativas de decisão em favor de instâncias participativas; b) o fortalecimento da articulação contra a hegemonia entre o local e o global, pois as experiências democráticas mundiais precisam de apoio de atores democráticos transnacionais; c) Ampliação do experimentalismo democrático que permite a pluralização cultural, racial e distributiva da democracia para que possam se multiplicar os experimentos em todas as direções (SANTOS, 2002, pp.77/78)
}

Saber Humano - Revista Científica da Faculdade Antonio Meneghetti. 
ainda precisa dirimir sérios entraves, especialmente educacionais, culturais e econômicos, porque predomina ainda uma cultura assistencialista do Estado, onde o serviço público é tido como se fosse uma oferta ou favor e não um direito do cidadão, bem como há uma crise de valores democráticos e de solidariedade. Isto reforça o sentimento anticívico, em que o indivíduo prefere perpetuar a prestação paternalista que o Estado oferece ${ }^{15}$ e a continuarem apáticos.

\section{APATIA POLÍtica DOS CIDAdÃOS E A CRISE NO EXERCÍCIO DA CIDADANIA}

A apatia política em síntese pode estar relacionada com comportamentos que acusam um grau elevado de conformismo político, ou ainda, com a satisfação com o funcionamento da democracia, podendo referir-se a comportamentos ativos ou passivos dos cidadãos.

Embora possa ser afirmado que a democracia não está em perigo, há de se reconhecer a sua decadência ${ }^{16}$ e a sua falta de qualidade à crise de cidadania ${ }^{17}$, evidenciada pela apatia dos cidadãos contemporâneos pela política e por uma passividade dos mesmos no tocante à participação na coisa pública.

Ao abordar a temática da qualidade da democracia, Ranieri alega que não basta a existência da democracia, mas sim democracias efetivas e de qualidade, pois a efetividade e a qualidade são pré-requisitos para a concretização dos direitos fundamentais ${ }^{18}$.

Essa tendência de descrédito, desilusão com os regimes democráticos e diminuição da participação política, é ocasionada por diversos ${ }^{19}$ fatores que contribuem para o seu alastramento $^{20}$ : como históricos de corrupção, religiosos, políticos, questões estruturais, de

\footnotetext{
${ }^{15}$ DUARTE, 2009.

${ }^{16}$ Habermas em conferência internacional sobre a democracia na Europa, em 28 de outubro de 2013, na Fundação Calouste Gulbenkian em Lisboa, falou da crise das democracias nacionais causada pela globalização e pela desregulação dos mercados e a necessidade de introduzir processos de legitimação democrática a nível supranacional. Segundo o filósofo, a forma como as decisões dos governos dos Estados-nação são cada vez mais insignificantes face ao peso das organizações internacionais. Esta perda de influência dos Estados-nação explica aquilo que Habermas nomeia de síndroma pós-democrática, ou seja, "as atitudes ambivalentes dos cidadãos nas democracias ocidentais", que decorre do "contraste entre a apatia e a alienação política crescente e a pressão de minorias ativas e grupos de protesto para mais democracia direta". Notícia retirada do sítio eletrônico $<$ http://www.publico.pt/mundo/jornal/saida-para-a-crise-da-democracia-e-tornala-transnacional-diz-habermas27318692>. Acesso em 20/06/2014.

${ }^{17}$ Segundo Yvonne Hébert e Alan Sears, há uma percepção generalizada de crise da cidadania, sobretudo por conta da baixa participação dos cidadãos nas questões de ordem política, colocando em risco o funcionamento do sistema político vigente (HÉBERT \& SEARS, 2002).

${ }^{18}$ RANIERI, 2009.

19 Muitos autores defendem que a desinformação dos cidadãos ligada à complexidade técnica das questões políticas, seria mais uma causa para dificultar a prática da intervenção do povo nas decisões políticas. (ZAMBUJA, 1968).

${ }^{20}$ URBANO, 2007, p. 523.
}

Saber Humano - Revista Científica da Faculdade Antonio Meneghetti. 
ordem pessoal, fraudes e fugas fiscais ${ }^{21}$, absentismo cívico e político, individualismo, consumismo, fatores e crises econômicos, culturais, sociais e declínio das formas tradicionais de participação política, como a militância partidária, déficit educacional, entre outros.

$\mathrm{Na}$ mesma linha, Bobbio registra sua preocupação com a apatia política decorrente do desinteresse da sociedade e advoga pela consolidação de amplos espaços sociais democráticos, como a escola, o trabalho e os ambientes familiares ${ }^{22}$. Para o autor, a apatia política dos cidadãos compromete o futuro da democracia, inclusive nos países mais desenvolvidos.

Na realidade, como consequência dessa crise de cidadania, os direitos de participação política e os objetivos constitucionais de realização da democracia econômica, social, cultural, ${ }^{23}$ bem como o aprofundamento da democracia participativa, garantido na Constituição não são observados, comprometendo a própria consolidação e fortalecimento do Estado Democrático de Direito.

Tendo em vista esse quadro atual, alguns autores, entre eles Stuart Mill, reforçam a tese da necessidade de uma educação que forme cidadãos ativos, participantes, capazes de julgar e escolher, características primordiais numa democracia, mas não necessariamente preferidos por governantes que confiam na tranquilidade dos cidadãos passivos.

Diante dos fatos explanados, constata-se que, em decorrência da crise de cidadania vivida por muitos Estados democráticos, surge a ideia de que o Estado e as instituições devem promover a educação democrática para os cidadãos, pois, como se sabe, cidadãos não nascem cidadãos, mas necessitam serem formados, educados quanto a seus direitos e quanto ao cumprimento de seus deveres, para que conscientes e instruídos possam lutar para atingir os objetivos constitucionais de participação política.

\section{O DiREITO FUNDAMENTAL À EDUCAÇÃo COMO INSTRUMENTO DE PREPARO PARA O EXERCÍCIO DA CIDADANIA NO ESTADO DEMOCRÁTICO DE DIREITO}

\footnotetext{
21 Sobre a questão das fugas fiscais vale lembrar os ensinamentos de Loureiro que diz que em sociedades como a portuguesa e as do sul da Europa o desrespeito ao dever fundamental de pagar impostos "agrava as condições de financiamento de um conjunto de bens públicos". Adeverte o autor que as fraudes fiscais lesam o Estado, todavia, essas atitudes não sofrem censura social grave, corroborando para que haja uma perda de relevância de uma cultura de deveres no espaço público e de importância do bem comum. (LOUREIRO, 2010, pp.21-22).

${ }^{22}$ BOBBIO, 1986.

${ }^{23}$ Gomes Canotilho e Vital Moreira dizem que o conceito de democracia econômica, social e cultural, previsto na Constituição Portuguesa é a fórmula constitucional para aquilo que os vários países, entre eles, o Brasil, designam por Estado Social, que se traduz na satisfação dos níveis básicos de prestações sociais para todos, e na eliminação das desigualdades sociais (CANOTILHO \& MOREIRA, 1993, p.66).
}

Saber Humano - Revista Científica da Faculdade Antonio Meneghetti. 
Imperioso dizer que a maioria dos países no mundo tutela em seus textos constitucionais o direito de acesso e a permanência de seus cidadãos à educação escolar básica. É notória de qualquer forma a importância da educação para o desenvolvimento humano, social e político, e foi com base nessas necessidades que vários países do mundo tendem a considerar a educação até certo nível, geralmente o ensino primário e secundário, como um direito fundamental.

Com efeito, sabe-se que o princípio da soberania popular impõe deveres, entre eles o do ensino fundamental obrigatório. Assim, a educação ou instrução básica é inserida na Constituição Brasileira como pilar de cidadania e como um importante instrumento para o preparo dos cidadãos para o exercício da participação política. A legislação Constitucional Brasileira no tocante ao direito à educação fundamental está centrada de acordo com os valores democráticos constitucionais e fundada no desenvolvimento da personalidade de cada indivíduo, na contribuição para o progresso social, na participação na vida política coletiva, fundamentos estes que se traduzem na necessidade de uma educação política que prepare para o exercício da cidadania.

Partilha-se do entendimento que se faz necessário ao cumprimento da exigência constitucional de preparo para o exercício da cidadania e objetivos de participação, primeiramente, o fornecimento da educação básica escolar. Isto porque, por exemplo, o domínio do código alfabético e das técnicas de leitura e escrita não apenas propiciam o acesso à informação, como permitem a participação do cidadão nos espaços em que estas técnicas são necessárias. Todavia, concomitante a importância da educação básica fundamenal para o exercício da cidadania também o é a educação política.

\subsection{A importância da educação política para o exercício da cidadania}

O ser humano não nasce como a deusa grega Atena, saída pronta, acabada e adulta da cabeça de Zeus. Já dizia Montesquieu ser impossível a consolidação de um regime democrático sem educação democrática.

Para ser plena, a cidadania exige que os indivíduos tenham conhecimentos sobre como funciona o ambiente político. Maria Victoria Benevides, ao abordar a importância da educação como sinônimo da capacidade de o indivíduo entender seus direitos e deveres na sociedade, diz que a educação política ocorre por meio de um processo de debate, busca por 
informação e participação ${ }^{24}$. Assim, a democracia apresenta como condição primordial para sua própria existência a exigibilidade de indivíduos capacitados para fazer escolhas.

No que diz respeito aos deveres dos indivíduos na sociedade, Casalta Nabais menciona três elementos constitutivos da cidadania: “a) a titularidade de um determinado número de direitos e deveres numa dada sociedade determinada; b) a pertença a uma específica comunidade política (normalmente o Estado), frequentemente vinculada à noção de nacionalidade; e c) a capacidade de contribuir para a vida pública dessa comunidade por meio da participação" 25 .

Conforme ensina Ferreira Filho, para que o indivíduo possa se governar é necessário que atinja certo grau de amadurecimento e experiência no trato da coisa pública, contudo, é imprescindível que tenha, no mínimo, certo nível cultural, e não apenas certo nível de alfabetização, não obstante ser difícil, mas não impossível, determinar esse nível. ${ }^{26}$.

É óbvio que o fato de os Estados proporcionarem uma educação escolar específica para a cidadania não corresponde a uma loteria premiada capaz de proporcionar mais participação política ou mesmo dar certeza de que serão formados futuros cidadãos participativos e comprometidos com os objetivos constitucionais de cidadania.

De toda forma, as gerações vindouras, caso se faça uma opção pela educação política e pela promoção da cultura política, serão ao menos de forma potencial, bem mais esclarecidas e conscientes de seus direitos e deveres do que a geração presente.

Assim sendo, mesmo considerando o ambiente de apatia à participação política dos dias atuais, marcado pela dissolução do espaço público ${ }^{27}$, ganha espaço, aparentemente sob o olhar paradoxal, no Brasil, em e em muitos países do mundo, o discurso de que é responsabilidade da escola a instrução cívica e a alfabetização política dos indivíduos voltada para o exercício e preparo da cidadania.

\footnotetext{
${ }^{24}$ BENEVIDES, 1991.

${ }^{25}$ NABAIS, 2006, p.638.

${ }^{26}$ FERREIRA FILHO, 2011.

${ }^{27} \mathrm{Na}$ obra "A condição Humana", Hannah Arendt afirma que os acontecimentos do século XX, da "Era Moderna", como a ascensão dos sistemas totalitários e da sociedade competitiva de consumo, permitiram a deterioração do espaço público, desencadeando o isolamento dos cidadãos, não apenas daqueles "excluídos da participação ativa no governo" do país, mas acima de tudo entre a sua própria classe" quanto às questões de interesse público. (ARENDT, 2007, p.363).
}

Saber Humano - Revista Científica da Faculdade Antonio Meneghetti. 


\subsection{Educação cívica escolar como via para a construção do cidadão participativo}

A educação para a cidadania compreende de modo geral quatro questões principais: a) a literacia política; b) o espírito crítico; c) as atitudes e os valores; e d) a participação ativa ${ }^{28}$.

Cumpre advertir, no entanto, que até hoje ela não foi adotada de forma tranquila e clara em grande parte de países, até mesmo em países de intensa participação popular, seja sob o argumento de muitos governos de que ela possui papel de doutrinação ou cunho ideológico $^{29}$, seja pelas muitas barreiras técnicas, financeiras, de conteúdo, didáticas, existentes nas políticas curriculares, necessitando de mais difusão, debate, inclusive interdisciplinar, para possibilitar concretas reformas a fim de que os objetivos constitucionais de cidadania não sejam simples folhas de papel.

Dessa maneira, objetiva-se debater se a educação para a cidadania garantida constitucionalmente, na legislação infraconstitucional no Brasil, tem sido adequada e suficiente para atingir os objetivos constitucionais de participação democrática.

Primeiramente cumpre desmistificar o argumento de governantes, partidos, entre outros segmentos, de que a educação para a cidadania como disciplina obrigatória apresenta viés partidário e, portanto, não poderia ser ofertado em sala de aula. Combatendo esses argumentos, afirma-se que se a intenção de um professor for realmente doutrinar partidariamente seus alunos, não será a falta de uma disciplina que tolherá sua conduta.

Embora concorde com o lecionamento da disciplina curricular como umas formas de preparar os indivíduos para atingir os objetivos constitucionais de participação e cidadania, partilha-se do entendimento de que a simples informação ou transmissão de conteúdos não é o suficiente, pois esta pode ser obtida de forma fácil, rápida, ao alcance de muitos, como bem fazem os meios de comunicação de massa.

\footnotetext{
${ }^{28}$ EURYDICE, 2012, p. 17.

${ }^{29}$ Nesse sentido ideológico foi o caso da "Educação Moral e Cívica" lecionada no Brasil no período ditatorial. (REZENDE, João Francisco. Educação escolar, hábitos e atitudes políticas: considerações sobre a experiência brasileira, In: DANTAS e all. Educação Política: reflexões e práticas democráticas.(Cadernos Adenauer XI (2010) $n^{\circ} 3$, p.22) e, por exemplo, também na Espanha no período franquista onde existia a matéria de "Formação do Espírito Nacional" nos currículos escolares. Em 2004, o governo espanhol adotou, assim como outros governos europeus, a resolução da Assembleia Geral das Nações Unidas sobre o Programa Mundial de Educação em Direitos Humanos, que recomendava a inclusão desses conteúdos no ensino obrigatório. Todavia, a celeuma gerada por diversos setores da população espanhola levou o governo a objetar e judicializar esta matéria curricular, que foi censurada por supostamente doutrinar os estudantes. Assim, a adesão dessa disciplina vem sendo imensamente discutida, e a controvérsia sobre a implementação deste assunto tem sido produto de confronto ideológico entre grupos políticos de diferentes sinais, pois para alguns essa educação de valores é contrária ao pluralismo, à autonomia regional, sendo a questão até levada ao Tribunal Constitucional bem como chegou ao Tribunal Europeu dos Direitos do Homem, em Estrasburgo (França) e no Conselho de Direitos Humanos das Nações Unidas em Genebra. Em 2012, esta se transformou, produto da vontade política expressa pelas urnas, denominando-se Educação Cívica e Constitucional. (PÉREZ, 2014, p.115).
}

Saber Humano - Revista Científica da Faculdade Antonio Meneghetti. 
Portanto, é primordial ir além da mera transmissão de conhecimentos, buscando para além deste, a formação que corresponda a um processo de sedimentação com mais profundidade, um processo que seja capaz de desenvolvimento integral do homem e de todas as suas potencialidades, de forma que a personalidade se molde em todas as dimensões, não só cívica e política, mas física, intelectual, social, moral, religiosa, profissional e econômica.

Sob outro prisma, há autores que defendem que não deve ser papel da escola por meio do ensino formal básico ensinar as pessoas a serem cidadãs, como se isso se restringisse a um conteúdo a ser transmitido ${ }^{30}$. Sob esse ponto de vista, Arroyo sustenta que os exemplos mais bárbaros de atrocidades cometidas sobre a espécie humana, como as do nazifascismo, foram geridos por povos que detinham os mais altos índices de escolaridade, defendendo que não basta ter conhecimento para ser virtuoso.

Sob outro ponto de vista, Adela Cortina fala que a educação cívica é um dos meios para se conseguir uma boa polis, buscar o bem comum e a participação política e deve ser iniciada na escola. Segundo a autora, a educação é um meio indispensável porque acredita que é possível aprender a ser cidadão como quase tudo o que é importante na vida ${ }^{31}$.

Em que pesem os argumentos contra ao lecionamento dessas disciplinas, a verdade é que a educação cívica em contexto educativo, em particular na escola, é adotada em muitos países do mundo ${ }^{32} \mathrm{e}$, da análise de várias pesquisas sobre educação cívica escolar bem como da leitura dos objetivos constitucionais de participação política presente na Constituição Brasileira é possível afirmar que os programas de educação cívica fornecidas pelo ensino formal nas escolas podem exercer um efeito relevante em seus alunos no sentido de torná-los mais conhecedores do sistema político e potencialmente capazes de compreenderem, assumirem e desenvolverem condutas políticas congruentes ao sistema democrático ${ }^{33}$.

Imperioso ressaltar que em nossos Estados Democráticos de Direito há uma necessidade de preparação e formação dos cidadãos para viver em sociedade, fazendo-se

\footnotetext{
${ }^{30}$ BORBA, 2010.

31 CORTINA, 2009.

32 Reforçando a intenção de garantir o preparo para a cidadania democrática e aumentar o conhecimento dos cidadãos sobre a utilização dos instrumentos democráticos, em 2010, todos os Estados-Membros da União Europeia adotaram a Carta do Conselho da Europa sobre Educação para a Cidadania Democrática e para Direitos Humanos. A Carta refere-se à educação para a cidadania democrática e à educação para os direitos humanos na qual estabelece, entre seus objetivos e princípios, o desenvolvimento e a promoção das práticas e atividades de ensino e de aprendizagem que valorizem os princípios e valores da democracia e dos direitos humanos, consagrando, sobretudo, a governança das instituições de ensino. Possui ainda a intenção de motivar a responsabilização e a participação ativa dos alunos, dos profissionais de educação e de outras partes interessadas, incluindo os pais. (Capítulo II, art. $5^{\circ}$, alínea $f$ da Carta do Conselho da Europa sobre Educação para a Cidadania Democrática e os Direitos Humanos).

${ }^{33}$ GALSTON, 2001.
}

Saber Humano - Revista Científica da Faculdade Antonio Meneghetti. 
necessários conhecimentos básicos sobre o funcionamento das instituições democráticas, de mecanismos de representação, dos direitos e deveres intrínsecos à cidadania. ${ }^{34}$. A visão constitucional brasileira de cidadania no tocante ao seu compromisso com a educação, conforme elencado no art. $205^{\circ}$ da Constituição, traduz a noção de "preparo" e de "exercício".

A educação não constitui a cidadania, no entanto fornece instrumentos básicos para seu exercício. Consubstanciado nisso, o art. $205^{\circ}$ ao afirma ser o objetivo da educação o "pleno desenvolvimento da pessoa, seu preparo para cidadania e sua qualificação para o trabalho" o que se pretendeu foi a opção pela formação integral, vinculando a educação à formação da cidadania. O legislador brasileiro almejou definir a educação como um processo amplo de formação do indivíduo que pode ocorrer não apenas na instituição escolar, consubstanciado em diversas maneiras de convivências sociais.

Diante disso, compreende-se que a educação básica deve garantir ao aluno condições para o desenvolvimento do cidadão participativo, proporcionando conhecimentos e práticas que efetivamente viabilizem os objetivos constitucionais de participação e os estabelecidos para a educação na Constituição Federal e na Lei de Diretrizes e Bases da Educação, bem como permita o exercício concreto dos direitos civis, políticos e sociais.

\section{O DIREITO À EDUCAÇÃO COMO UM DIREITO HABILITANTE PARA O EXERCÍCIO DA PARTICIPAÇÃO POLÍTICA E APRIMORAMENTO DA DEMOCRACIA}

A importância do direito fundamental à educação é inegável e envolve elementos de direitos sociais, culturais ${ }^{35}$, econômicos e políticos em um só direito, permitindo o exercício das liberdades individuais e coletivas. Para o presente caso, possibilita também o exercício dos direitos de participação e dos mecanismos de democracia participativa, como o direito de petição; o direito ao voto; plebiscito; referendo; iniciativa popular, entre outros.

Tal concepção foi explicitada pelo Comitê dos Direitos Econômicos, Sociais e Culturais, no seu Comentário Geral 11 (E/C.12/1999/4), o qual enuncia que o direito à educação:

Foi classificado, de vários modos, como um direito econômico, um direito social e um direito cultural. É tudo isso. É também, de muitos modos, um direito civil e um direito político, dado que também é central para a realização plena e efetiva destes direitos.

\footnotetext{
${ }^{34}$ RANIERI, 2009.

${ }^{35}$ Sobre essa temática, Reis Monteiro, afirma que o direito à educação tem um conteúdo transversal (crossectoral nature) e que o direito à educação é geralmente incluído na categoria dos direitos culturais, mas o seu conteúdo atravessa as outras categorias de direitos. (MONTEIRO, 2013. p.18);
}

Saber Humano - Revista Científica da Faculdade Antonio Meneghetti. 
Nesse sentido, pode ser afirmado que o direito à educação, mais do que qualquer outro, trata-se de "um direito de empoderamento" (empowerment right), não apenas pelo fato de fornecer desenvolvimento pessoal, moral e autonomia intelectual a cada pessoa humana, mas como um contributo para a mobilidade social, sendo que desse desenvolvimento depende o conhecimento de outros direitos.

Reafirmando a importância do direito fundamental à educação, Canotilho afirma que a realidade do nível de ensino de um Estado e outros dados reais "condicionam decisivamente o regime jurídico-constitucional do estatuto positivo dos cidadãos" 36 .

Com efeito, a ideia da educação como direito "troncal" e habilitante para aquisição de outros direitos ocupa lugar de destaque no seio dos direitos fundamentais, pois é um instrumento essencial ao desenvolvimento da pessoa em si e ao exercício dos demais direitos civis, econômicos, sociais, culturais, sedimentando a ideia da cidadania como o "direito de ter direitos" 37 .

Desse modo, entender a educação como um direito habilitante para o exercício da participação política e para o aprimoramento da democracia se faz relevante, pois o cidadão desprovido do saber necessário ao gozo de suas liberdades, do conhecimento de seus direitos e do exercício de suas obrigações, encontra-se negado em sua dignidade.

O direito à educação não é ideologicamente imparcial, muitos dispositivos presentes na Constituição Brasileira dispõem sobre a sua finalidade, com juízos de valor. A promoção do ideal republicano e democrático, disposto no art. $1^{\circ}$ da Constituição Brasileira faz parte do conteúdo político nuclear do direito à educação.

Nesse sentido, o direito à educação corresponde a necessidades individuais e coletivas e o seu conceito no Estado Democrático de Direito não pode ser separado dos objetivos fundamentais da República Brasileira (art. $3^{\circ}$ da CRB). Essas expectativas manifestam-se nas exigências da cidadania que demandam participação política e contribuição individual e coletiva para a edificação das aspirações nacionais. Neste contexto, "os indivíduos não podem considerar desligados ou irresponsáveis pelos valores que fundamentam o regime jurídico que lhes assegura os próprios direitos" ${ }^{\prime 38}$.

Feitas essas considerações, percebe-se que quando o assunto é o preparo para o exercício da cidadania a maioria dos países centra suas políticas educacionais de acordo com os valores democráticos constitucionais. Identifica-se aqui a relevância da afirmação, pois o

\footnotetext{
${ }^{36}$ CANOTILHO, 2003, p.473.

${ }^{37}$ HARENDT apud RANIERI, 2012.

${ }^{38}$ RANIERI, 2009, p. 289.
}

Saber Humano - Revista Científica da Faculdade Antonio Meneghetti. 
direito à educação básica e política significa educar para a participação que por consequência permite o aperfeiçoamento da democracia.

\section{CONSIDERAÇÕES FINAIS}

A Constituição democrática do Brasil caracteriza-se pelo seu preciosismo principiológico, garantidoras da ampla participação política por meio do modelo representativo e mecanismos de participação, bem como sinalizam a possibilidade do desenvolvimento do modelo participativo em complementação ao representativo.

Todavia, o modelo democrático-representativo mostrou-se insuficiente para atender aos anseios sociais e permitir a real manifestação da vontade de todos os cidadãos, culminando em uma crise de representatividade que acarreta um sentimento de apatia política, de insatisfação social com o governo, dando margem para o enfraquecimento da participação na res publica e aumento da distância entre governantes e governados. A mudança nesse cenário é urgente. "A participação é um antídoto contra a tirania"39 e, portanto, deve ser entendida como um instrumento de defesa dos próprios cidadãos.

A escolaridade básica é um direito-dever de dupla natureza que tem a função de tutelar a dignidade do cidadão, a garantia de um mínimo de igualdade de oportunidades e, também, da preservação e do funcionamento regular de um Estado Democrático moderno. ${ }^{40}$ Isto porque, conforme visto, “o direito à educação tem no Estado não só um prestador por excelência", mas ainda um "beneficiário do direito" em virtude do regime democrático vigente $^{41}$. De fato, não é suficiente que a Constituição garanta os mecanismos de participação política, nem que enuncie e associe o direito à educação a esses objetivos, se não garantir sua concreta fruição. O direito à educação básica, embora essencial e adequado ao preparo para o exercício da cidadania, manifestamente torna-se insuficiente para levar a cabo a construção diária dos ideais democráticos e os fundamentos constitucionais de participação política. Para atingir tal objetivo, é necessário um grande esforço de educação, não apenas aquela garantida pelo Estado na forma do direito fundamental à educação básica, mas também uma política, da qual a educação cívica escolar faça parte. Assim, torna-se proeminente começar a incutir na mentalidade coletiva das pessoas essa exigência constitucional de preparo para a cidadania ${ }^{42}$,

\footnotetext{
${ }^{39}$ CORTINA, 1999, p. 101.

${ }^{40}$ ANDRADE, 2001.

${ }^{41}$ RANIERI, 2009 , p.354.

${ }^{42}$ RANIERI, 2009.
}

Saber Humano - Revista Científica da Faculdade Antonio Meneghetti. 
cujo sentido se configura na própria exigência de conservação e aprimoramento do Estado Democrático de Direito.

Constatou-se que a aprendizagem de conteúdos específicos para a preparação do indivíduo para a cidadania não garante que haverá zelo pelas instituições democráticas e efetiva participação política para além do voto obrigatório, a instituição escolar deve cumprir o seu papel de iniciação no mundo, na cultura, tradições públicas ${ }^{43}$ e realizar os objetivos educacionais de preparação para o exercício da participação. Dessa maneira, entende-se que a educação política assim como a instrução obrigatória referente ao direito fundamental à educação são essenciais e adequadas, mas ainda não são por si só suficientes. Uma verdadeira educação que prepare para o exercício da cidadania é aquela promovida por processos educacionais contínuos que visem à participação política que não ocorre apenas nas instituições escolares de ensino básico em forma de disciplina, mas é promovida e realizada por várias instituições e organizações, tais como pela família, clubes, igrejas, sindicatos, associações, empresas, órgãos do Estado, como Judiciário, escolas do Legislativo, organizações não governamentais, fundações, jornais, recursos eletrônicos, instituições culturais, entre outros canais.

Essa mudança deve ser iniciada com uma educação que promova uma maior participação e, para tanto, é preciso começar antes de tudo a promover a participação em nível local, sobretudo nas escolas, em associações diversas, de bairros, movimentos cívicos e religiosos, pois a participação induz participação. ${ }^{44}$ Somente a partir daí que se poderá ter uma democracia mais participativa ${ }^{45}$, em que Estado e sociedade se aproximem, com a contínua inclusão dos membros na respectiva comunidade, de forma que todos dividam um mesmo "denominador comum, um mesmo chão comum, que assim os torne cidadãos de corpo inteiro dessa comunidade" 46 .

\footnotetext{
${ }^{43}$ FURTADO, 2010.

${ }^{44}$ OLDFIELD, 1990.

${ }^{45}$ COSTA, 2011.

${ }^{46}$ NABAIS, 2006, p. 638.
}

Saber Humano - Revista Científica da Faculdade Antonio Meneghetti. 


\section{REFERÊNCIAS BIBLIOGRÁFICAS}

ALMOND, G; VERBA, S. The civic culture: political attitudes and democracy in five nations. Princeton: Princeton University Press, 1989.

ANDRADE, Vieira. Os Direitos Fundamentais na Constituição da República Portuguesa de 1976. 2 ed. Coimbra: Almedina. 2001.

ARENDT, Hannah. As Origens do totalitarismo. Trad. Roberto Raposo. São Paulo: Cia das Letras, 2007.

ARENDT. Hannah. As Origens do totalitarismo. Trad.: Robert Raposo. São Paulo: Cia das Letras, 1989.

BENEVIDES, Maria Victoria. A Cidadania Ativa. Referendo, Plebiscito e Iniciativa Popular. São Paulo: Ática S.A., 1991.

BOBBIO, Noberto. O Futuro da Democracia. 6 ed. São Paulo: Paz e Terra, 1986.

BORBA, Dalton José. BLAUTH, Flávia Noemberg Lazzari. A Educação para o Exercício da cidadania: uma análise crítica e transdiciplinar do analfabetismo jurídico. Conpedi: Ceará, 2010.

CANOTIlHO, J.J. Gomes. Direito Constitucional e Teoria da Constituição. 7 ed. Coimbra: Almedina, 2003.

CANOTIlHO, JJ. MOREIRA, Vital. Constituição da República Portuguesa Anotada. 3 ed. Coimbra: Coimbra Editora, 1993.

CASTORIADIS, Cornelius. As encruzilhadas do labirinto III: o mundo fragmentado. Tradução de Rosa Maria Boaventura, São Paulo: Paz e Tera, 1992.

COMPARATO, Fábio Konder. A nova cidadania. Lua Nova: Revista de Cultura e Política. São Paulo: Abril, no 28-29, 1993.

CORTINA, Adela. Ciudadanos del mundo. Madrid: Alianza Editorial, 1997.

CORTINA, Adela. Ciudadanos del mundo. Madrid: Alianza Editorial, 2009.

CORTINA, Adela. Los ciudadanos como protagonistas. Barcelona,1999.

COSTA, Denise Souza. O Direito fundamental à educação, democracia e desenvolvimento sustentável. Belo Horizonte: Fórum, 2011.

COSTA, Marta Nunes da. Constituição, Democracia e Orçamento ParticipativoPerspectiva Comparada entre Brasil e Portugal. Revista da Faculdade de Direito da Universidade Federal de Minas Gerais. No 59, Jul/Dez. Belo Horizonte: Nova Fase, 2011. 
DALLARI, Dalmo de Abreu. Educação e Preparação para a Cidadania. In: BENEVIDES, Maria Victoria; BERCOVICI, Gilberto, MELO; Claudineu (organização). Direitos Humanos, Democracia e República. Homenagem a Fabio Konder Comparato. São Paulo: Editora Quartier Latin do Brasil, 2009.

DANTAS, Humberto. Apresentação: $O$ caráter essencial da educação política e o desenvolvimento da democracia no Brasil: In: Educação Política: reflexões e práticas democráticas. Cadernos Adenauer XI (2010) n³.

DUARTE, Ana Catarina. Cidadania e cultura política: estudo do orçamento participativo em Portugal (2000-2008). Universidade Técnica de Lisboa - Instituto Superior de Ciências Sociais e Políticas, Lisboa, 2009.

EURYDICE. A educação para a cidadania na Europa. Lisboa: Eurydice, novembro de 2012, ISBN-978-972-614-549-3.

FERREIRA FILHO, Manoel Gonçalves. Curso de Direito Constitucional. 37 ed. revista e atualizada. São Paulo: Saraiva, 2011.

FREIRE, Paulo. Pedagogia do oprimido. Rio de Janeiro: Paz e Terra, 1987.

FREIRE, Paulo. Política e educação. 5 ed. São Paulo: Cortez, 2001.

GALSTON, W. Political Knowledge, Political Engagement, and Civic Education. Annual Review of Political Science, v. 4, 2001.

HÉBERT, Yvonne, SEARS, Alan. Citizenship Education. Canadian Education Association: Canadá, 2002.

LENZA, Pedro. Direito Constitucional Esquematizado. 14 ed. São Paulo: Saraiva, 2010.

LOUREIRO, João Carlos. Adeus ao Estado Social? Coimbra: Coimbra Editora, Novembro de 2010 .

LUÑO, Antonio Enrique Perez. Derechos Humanos, Estado de derecho y Constitución. 8 ed. Madrid: Tecnos, 2003.

MARTINS, Maria José D., MOGARRO, Maria João. A Educação para a cidadania no século XXI. Revista Iberoamericana de Educação, no 53 2010, (ISSN: 1022-6508).

MONTEIRO, A. Reis. Sobre o Direito à Educação. Artigo disponibilizado em aulas de Pós Graduação de Direitos Humanos pela Faculdade de Direito da Universidade de Coimbra, 2013.

NABAIS, Casalta. Solidariedade Social, Cidadania e Direito Fiscal. In: Estudos Jurídicos e Económicos em Homenagem ao Prof. Doutor António de Sousa Franco. Volume II, Edição da Faculdade de direito da Universidade de Lisboa. 2006.

PÉREZ, Teresa González. La educacíon Cívica en España: Retrospectiva y Perspectiva. Vol. 18, n.42, jan/abr, 2014.

Saber Humano - Revista Científica da Faculdade Antonio Meneghetti. 
RANIERI,Nina Beatriz Stocco. O Estado Democrático de Direito e o sentido da exigência de preparo da pessoa para o exercício da cidadania pela via da educação. Tese apresentada à Faculdade de Direito da Universidade de São Paulo para obtenção do título de livre-docente. São Paulo, 2009.

RANIERI,Nina Beatriz Stocco. O Regime Jurídico do Direito à Educação na Constituição Brasileira de 1988 In: Estudos em Homenagem ao Professor Dr. Jorge Miranda, Vol. III Coimbra: Coimbra Editora, Faculdade de Direito de Lisboa, 2012.

REZENDE, João Francisco. Educação escolar, hábitos e atitudes políticas: considerações sobre a experiência brasileira. In: DANTAS e all. Educação Política: reflexões e práticas democráticas. Cadernos Adenauer XI (2010) N³, p.22).

URBANO, Maria Benedita Malaquias Pires. Cidadania para uma democracia ética. Boletim da Faculdade de Direito de Coimbra. (Separata), vol. LXXXIII, 2007.

ZAMBUJA, Darcy. Teoria Geral do Estado. Porto Alegre: Editora Globo, 1968.

\section{Sites Consultados}

DALlARI, Dalmo de Abreu. Direitos e Deveres de Cidadania. Disponível em $<$ http://www.dhnet.org.br/direitos/sos/textos/deveres.htm> Acesso em 29/04/2014

FERREIRA, CASTORIADIS, Cornelius. As encruzilhadas do labirinto II: os domínios do homem. São Paulo: Paz e Terra, 2002a., p. 334 apud FERREIRA, Evandson Paiva. Paidéia democrática: da heteronomia à autonomia do agir ético - uma interrogação sobre o pensamento de cornelius castoriadis. p.4, Disponível em: http://anaisdosimposio.fe.ufg.br/up/248/o/1.2._30_.pdf.Acesso em 01/10/2014. 